\title{
Tutoria na Educação a Distância: proposta do curso de licenciatura em pedagogia a distância da Universidade Federal do Rio Grande do Sul - UFRGS
}

\section{Tutoring in distance education: proposal of the licentiate distance learning course in pedagogy from Universidade Federal do Rio Grande do Sul - UFRGS}

\author{
Dr $^{\text {nd }}$. Lilian Schwab Gelatti ${ }^{1}$ \\ Dr $^{\text {nd }}$. Vânia Ben Premaor ${ }^{2}$ \\ $\mathrm{Ms}^{\text {nd }}$. Alexandre Ramos de Araújo ${ }^{3}$
}

\begin{abstract}
RESUMO
Este artigo apresenta a proposta pedagógica de atuação da tutoria do Curso de Graduação em Pedagogia a Distância - Licenciatura (PEAD), da Faculdade de Educação da UFRGS (Brasil). Discute as funções pedagógica, social e organizativa dos tutores a partir das diretrizes teórico-práticas do Curso. Palavras-chave: tutoria; proposta pedagógica; educação a distância; educação superior.
\end{abstract}

\begin{abstract}
This article presents the tutoring pedagogical approach from the distance learning Undergraduate Course in Pedagogy - Licentiateship (PEAD), from the Education College of UFRGS (Brazil). It discusses the pedagogical,
\end{abstract}

1 Doutoranda em Educação pela Universidade Federal do Rio Grande do Sul (UFRGS). Professora da Universidade Estadual do Rio Grande do Sul (UERGS) e dos Cursos de Licenciatura em Pedagogia a Distância (PEAD) e de Especialização em Tecnologias da Informação e da Comunicação na Promoção da Aprendizagem (PROA) pela UFRGS, Brasil. E-mail: 1iliangelatti@ gmail.com

2 Doutoranda em Educação pela Pontifícia Universidade Católica Argentina (UCA). Tutora do Curso de Especialização em Tecnologias da Informação e da Comunicação na Promoção da Aprendizagem (PROA) pela UFRGS, Brasil. Membro do Departamento TIC de Buenos Aires/ Argentina. E-mail: eadvirtuale@gmail.com

3 Mestrando em Educação pela Universidade Federal do Rio Grande do Sul (UFRGS). Professor de Matemática do Colégio Adventista de Esteio/RS/Brasil. E-mail: alexandreraraujo@yahoo.com.br 
social and organizing tutors' functions according to the course's theoretical-practical guidelines.

Keywords: tutoring; pedagogical approach; distance education; higher education.

\section{Introdução}

O interesse do presente grupo de pesquisadores, autores desse $\operatorname{artigo}^{4}$, no Curso de Graduação em Pedagogia - Licenciatura da Faculdade de Educação da Universidade Federal do Rio Grande do Sul (PEAD/FACED/UFRGS), oferecido na modalidade de educação a distância (EAD), deve-se à relevância e repercussão dessa proposição formativa no universo acadêmico pela sua diferenciada visão tecnológico-educacional e de tutoria frente às diversidades de propostas pedagógicas e de funções tutoriais encontradas no contexto da EAD, tanto no Brasil como em outros países. Esse foi o primeiro curso de licenciatura a distância da UFRGS, constituindo-se em um exemplo singular para as sucessivas iniciativas de EAD em diversas áreas de conhecimento da universidade.

Este Curso, partindo do propósito de graduar 400 alunos(as) - que são, na maioria, professoras da educação básica atuantes em escolas públicas estaduais e municipais do estado do Rio Grande do Sul - contempla necessidades políticoeducacionais do Ministério da Educação (MEC/Brasil), tal como o investimento na formação inicial e continuada de professores no contexto brasileiro. Nesta perspectiva, a escola pública é, conforme Santos (2005, p. 84), um dos principais compromissos da universidade. Diante da atual conjuntura sócio-educacional, compreende-se entre as diretrizes para uma necessária reforma progressista e democrática da universidade pública, que permita responder aos desafios que se apresentam no início do século XXI: "a valorização da formação inicial e sua articulação com os programas de formação continuada" e "a reestruturação dos cursos de licenciatura de forma a assegurar a integração curricular entre a formação profissional e formação acadêmica" (SANTOS, 2005, p. 84). Essas diretrizes, entre outras, justificam a proposta formativa em estudo.

Pretende-se que esta apresentação da proposta da atuação dos tutores do Curso de Pedagogia a distância (PEAD/UFRGS) contribua com a própria univer-

4 Este artigo partiu do trabalho proposto na disciplina Tutoria em Educação a Distância I, ministrada pelas Prof.as Dras. Rosane Aragon de Nevado (Coordenadora Geral do Curso PEAD) e Marie Jane Carvalho (Vice-Coordenadora do Curso PEAD), dos Programas de Pós-Graduação em Educação (PPGEDU) e em Informática na Educação (PPGIE) da UFRGS/Brasil. 
sidade e com outras instituições de ensino, com o objetivo de possibilitar pontos e contrapontos teórico-práticos nesse campo e subsidiar o aprimoramento pedagógico da tutoria na EAD. Para isso, expõem-se, a seguir, três tópicos articulados: a) a proposta de atuação da tutoria; b) os recursos informatizados utilizados pela tutoria e demais partícipes do Curso, como docentes e alunos; c) ponderações sobre a concretização da proposta pedagógica de atuação da tutoria.

\section{Proposta de Atuação da Tutoria do Curso PEAD/UFRGS}

O Guia do Tutor (CARVALHO; NEVADO; BORDAS, 2006c) consiste num dos principais referenciais teóricos orientadores da proposta conceitual e prática dos tutores do Curso PEAD/UFRGS. Esse Guia foi um dos manuais analisados na fundamentação deste artigo quanto à proposição do projeto político-educacional do Curso. De acordo com este referencial, a Licenciatura em Pedagogia a distância foi criada a partir de um consórcio entre a Faculdade de Educação da Universidade Federal do Rio Grande do Sul (UFRGS) e o Centro de Ciências da Educação da Universidade Federal de Santa Catarina (UFSC), com o objetivo de "[...] graduar professores que já estão exercendo a docência [...] em escolas públicas estaduais e municipais do Estado do Rio Grande do Sul" (p. 15). Para isto, foram criados cinco polos: Polo de Alvorada; Gravataí; Sapiranga; São Leopoldo e o de Três Cachoeiras. Todos dispõem de laboratório de informática, biblioteca, salas para atividades coletivas, sala para tutores, docentes e coordenação de polo, recursos multimídia para atividades a distância e presenciais, a fim de atender à demanda de necessidades dos(as) alunos(as) de um curso universitário a distância.

Como princípio norteador do Curso PEAD, há o entendimento de que a formação do profissional da educação deve partir das "[...] diferentes compreensões de mundo, explicitadas em suas práticas docentes" e dos "processos de construção da vida humana e de transformação do mundo do trabalho" (2006c, p. 19). Por isso, considerando princípios construtivistas, o Curso tem como ponto de partida as experiências de vida e trabalho dos alunos, buscando desencadear reflexões e tomadas de consciência sobre essas experiências a partir de subsídios teórico-práticos que possibilitem a construção de conhecimentos e de práticas pedagógicas que melhor atendam aos objetivos sócio-educacionais almejados. Neste contexto, a implicação educacional consiste em compreender "a importância do trabalho de sala de aula como um espaço interativo e ágil 
de descoberta e criação individual e coletiva do conhecimento científico e de desenvolvimento de competências para o exercício da participação crítica e responsável nos processos sociais" (2006c, p. 19).

Quanto aos pressupostos do projeto pedagógico, o PEAD consiste, ao mesmo tempo, num curso de formação inicial e continuada de professores. Devido a esta especificidade, o Projeto Pedagógico do Curso organiza-se em torno de três pressupostos básicos:

autonomia relativa da organização curricular, considerando as características e experiências específicas da clientela - professores em serviço; a relação entre Prática Pedagógica e Pesquisa como elemento aglutinador dos demais componentes do currículo, constituindo-se em estratégia básica do processo de formação de professores; articulação dos componentes curriculares entre si, no semestre e ao longo do Curso. (2006c, p. 19, grifo dos autores)

Relacionado ao objetivo geral do Curso, que se destina à formação de professores em exercício, propõe-se preparar o professor (aluno do curso) para "[...] a reflexão teórica - meta-reflexão - permanente e a recriação das práticas escolares, ao ampliar o conhecimento e o pensamento sobre o fazer pedagógico" (2006c, p. 20). Como proposta metodológica, o PEAD "[...] reforça a articulação dos componentes curriculares entre si, no semestre e ao longo do Curso, bem como sua ligação com a prática pedagógica realizada nas escolas, em que os alunos-professores desenvolvem a docência" (p. 21), no sentido de estabelecer relações mais próximas entre o universo acadêmico e o escolar. Portanto, o Curso caracteriza-se pelo:

compartilhamento de ação por professores [docentes do curso] de diferentes áreas de conhecimento, no espaço das Interdisciplinas; trânsito constante entre a prática e a teoria; presença de um eixo articulador por semestre; trabalho dos professores [docentes do curso] no sentido de formar comunidades de aprendizagem com a intenção de que seus membros aprendam juntos; desenvolvimento de planejamento conjunto das atividades do semestre para garantir a desejada integração. (2006c, p. 21) 
A respeito da tutoria no Curso PEAD/UFRGS (2006c, p. 24), foco deste trabalho, foram previstos quatro tutores por polo em cada semestre do Curso, atendendo a turmas de 20 alunos, totalizando em torno de 20 horas semanais por tutor. Tanto os tutores da sede (os "a distância", distribuídos por interdisciplinas) como os tutores do polo (os "presenciais", distribuídos por polos) têm a função de atender às demandas de determinado polo. Segundo a proposta do Curso, o tutor deve estabelecer uma conexão junto aos alunos, a qual "[...] preze pelo clima cordial, humano, provocador, que auxilie nas dúvidas no processo de aprendizagem, analise e responda aos trabalhos acadêmicos realizados, sempre motivando a clientela do curso" (2006c, p. 24).

São atribuições do tutor do Curso PEAD, entre outras, que abrangem as funções pedagógica, social e organizativa:

comentar os trabalhos realizados pelos alunos; corrigir avaliações dos estudantes; ajudá-los a compreender os materiais do curso, através das discussões e explicações; responder às questões sobre a instituição; ajudar aos alunos a planejarem seus trabalhos; organizar círculos de estudo; fornecer informações por telefone, fax-símile e e-mail; supervisionar trabalhos práticos e projetos; atualizar informações sobre o progresso dos estudantes; fornecer feedback aos coordenadores sobre os materiais dos cursos e as dificuldades dos estudantes; servir de intermediário entre a instituição e os alunos; comentar os trabalhos escritos; colaborar na compreensão do material pedagógico, através da discussão e levantamento de questões; responder às perguntas dos alunos; ampliar temas das Unidades Didáticas pouco elaboradas; orientar trabalhos, projetos etc.; participar dos encontros presenciais; intermediar, quando necessários, as relações entre os estudantes e a coordenação do curso. (2006c, p. 24-25)

Quanto às funções do tutor do Curso PEAD, apresentam-se a seguir quadros explicativos do Guia do Tutor (2006c, p. 25-27), os quais especificam as funções tanto do tutor do polo como do da sede: 


\section{ACOMPANHAMENTO}

O tutor não tem, necessariamente, formação específica em qualquer área das Interdisciplinas. Sua função geral é proporcionar motivação, feedback, diálogo, orientação personalizada e orientação coletiva em atividades presenciais e coletivas, bem como estabelecer vínculos com cada estudante. $-\mathrm{N}^{\circ}$ de alunos: 20; -Local de atendimento: polos; -Tipos de atendimento: presencial, direto com os estudantes; $-\mathrm{CH} /$ semanal: 20 horas

\section{FUNÇÃO}

\section{Função Pedagógica}

- Ajudar cada aluno a planejar sua aprendizagem e o seu envolvimento no curso.

- Mapear e registrar, conjunta e periodicamente, com cada estudante: os interesses, as necessidades e as habilidades.

- Analisar sistematicamente o webfólio educacional com vistas à orientação, bem como manter a equipe da Interdisciplina informada.

- Incentivar cada aluno a acompanhar e realizar todo o trabalho solicitado.

- Organizar, conduzir e acolher grupos de estudos.

- Incentivar a criação e manutenção de comunidades de interesse on-line entre os estudantes.

- Desenvolver uma pedagogia da pergunta com vistas a facilitar que os alunos esclareçam seus pensamentos e enfrentem suas contradições e inconsistências.

- Incentivar a leitura de livros acadêmicos e de literatura em geral.

- Atuar como mediador e facilitador nas discussões acadêmicas presenciais, sobretudo manter postura acolhedora.

\section{Função Social}

- Criar ambiente agradável e acolhedor para a aprendizagem dos alunos.

- Atuar como coordenador e incentivador à participação individual e coletiva.

- Criar condições para que os alunos estabeleçam parcerias com outros colegas ao sugerir grupos com afinidades temáticas.

- Estabelecer e fortalecer vínculos com cada aluno.

- Chamar os alunos para estarem presentes no ambiente on-line. Sob hipótese alguma, permitir que um aluno se ausente por mais de uma semana do ambiente.

- Demonstrar prontidão para buscar o aluno e acolher sua justificativa, estabelecendo um novo contrato de trabalho.

- Zelar, discutir e incentivar abordagens, ideias e comportamentos éticos. 


\section{Função Organizativa}

- Estabelecer com cada aluno uma agenda de tempos e realizações.

- Zelar pelas regras, procedimentos, normas de acordo com as orientações da equipe do projeto.

- Acompanhar as atividades propostas pela equipe do eixo.

- Aplicar atividades definidas por Interdisciplina.

- Informar aos professores (docentes do curso) todas as questões pedagógicas referentes a cada aluno como ausências, afastamentos, dificuldades, alternativas.

- Manter contato com a coordenação do eixo e com a coordenação geral.

- Manter contato permanente com os tutores das Interdisciplinas.

- Manter o diário de bordo atualizado sobre suas atividades, dificuldades, realizações e solicitações (formato on-line).

- Realizar relatórios mensais sobre a turma de sua responsabilidade (formato online).

- Registrar casos particulares de dificuldades pedagógicas.

\section{II) FUNÇÃO DE APOIO DOCENTE AO TUTOR NA SEDE}

\section{ACOMPANHAMENTO}

O tutor tem formação geral ou específica nas Interdisciplinas. Ele deve facilitar e acompanhar $\mathrm{o}$ acesso dos estudantes aos enfoques temáticos e às atividades relacionadas. $-\mathrm{N}^{\circ}$ de alunos: 20; -Local de atendimento: sede (FACED/UFRGS); -Tipo de atendimento:on-line; - $\mathrm{CH} / \mathrm{semanal}$ : 20 horas

\section{FUNÇÃo}

\section{Função Pedagógica}

- Disponibilizar e fornecer informações, acompanhar e orientar sobre as atividades propostas na Interdisciplina.

- Trabalhar a partir da pedagogia da pergunta - propor perguntas que ajudem os alunos a descobrir possíveis contradições ou inconstâncias em suas contribuições nos fóruns e webfólio educacional.

- Realizar intervenções diretas, com a anuência da equipe, nas atividades realizadas e registradas no webfólio educacional.

- Dialogar com o tutor do polo sobre a realização das atividades.

- Acompanhar o entendimento de cada aluno sobre as atividades e o conteúdo dos enfoques temáticos.

- Analisar e sugerir realizações no webfólio educacional, a partir das orientações nas Interdisciplinas. 


\section{Função Social}

- Incentivar a troca de experiências e informações entre os estudantes sobre os enfoques temáticos.

- Acolher as dúvidas e as sugestões dos estudantes.

- Aceitar críticas e desenvolvê-las como desafio.

- Zelar, discutir e incentivar abordagens, ideias e comportamentos éticos.

\section{Função Organizativa}

- Dialogar constantemente com a equipe do eixo e, em especial, com a equipe da Interdisciplina, pela qual também é responsável.

- Informar e solicitar ajuda para questões pedagógicas específicas da Interdisciplina e dos enfoques temáticos.

- Realizar relatórios parciais mensais sobre a turma e sua aprendizagem.

- Registrar os casos particulares de ausências ou dificuldades nas atividades e no ambiente.

- Relatar à equipe do eixo as dificuldades na compreensão dos alunos sob sua responsabilidade.

- Manter o diário de bordo atualizado sobre suas atividades, dificuldades, realizações e solicitações.

Essas funções da tutoria do polo e da sede do Curso PEAD são presenciadas na atuação dos tutores, tendo em vista as características de cada interdisciplina, do docente e dos alunos de determinado polo. Conforme a demanda, as exigências e necessidades em questão, as atribuições da tutoria tomam diferentes configurações, podendo, por exemplo, um tutor do polo apresentar ações específicas ao seu polo, ou ainda, um tutor de sede ter que realizar mais funções pedagógicas e sociais do que outro tutor em outra interdisciplina que realiza mais funções organizativas. Porém, cabe a todos os tutores estarem preparados para realizar todas as funções apresentadas na proposta pedagógica do PEAD, até porque diversificados desafios são apresentados a cada eixo articulador (organizador do semestre letivo) do Curso.

Além disso, há diferenças entre os tutores no que se refere à formação acadêmica e apropriação tecnológico-educacional, muito embora sistemáticas propostas de trabalho presenciais e virtuais de formação inicial e continuada de tutores sejam promovidas no decorrer do desenvolvimento do Curso.

O Curso PEAD abrange aulas e/ou encontros presenciais entre docentes e alunos, geralmente ocorridos nos polos, além dos virtuais, sendo que tanto os tutores da sede como os do polo participam desses espaços/tempos presenciais como apoio docente. Também os tutores do polo, assim como os da sede, interagem com os alunos por meio de ambientes virtuais disponibilizados pelo Curso. Ademais, como uma de suas funções, o tutor da sede (com mais frequência) 
e o do polo participam também de reuniões presenciais sistemáticas de trabalho com docentes e/ou coordenadores, com outros tutores da mesma interdisciplina, com os de outras interdisciplinas e/ou com os dos polos do Curso.

Há uma dinâmica de ações por parte da coordenação do curso em manter o corpo de tutores ao longo do Curso e em investir na sua qualificação continuada. No entanto, se um tutor não corresponder às expectativas do Curso no que compete ao cumprimento efetivo de suas atribuições, ele poderá ser desligado do PEAD, abrindo assim novas oportunidades para outros interessados e habilitados a compor a tutoria.

Além da tutoria, há uma política de manutenção das coordenações dos polos - que são, em sua maioria, docentes ou doutorandos da área educacional da UFRGS - as quais apresentam funções pedagógicas e administrativas no Curso. A Interdisciplina Seminário Integrador, presente em todos os eixos articuladores do Curso, é ministrada pelo Coordenador do polo que busca, entre outros, promover articulações teórico-práticas entre as interdisciplinas (além das que são propostas pelas próprias interdisciplinas); estabelecer vínculos de reciprocidade entre alunos e demais partícipes do Curso; acompanhar, mediar e fazer proposições quanto ao trabalho desenvolvido pelos tutores da sede e do polo.

Esse investimento na continuidade e no fortalecimento da equipe da tutoria favorece o desenvolvimento de um trabalho mais coeso e unificado - não no sentido de "uniforme", pois se propõe valorizar as diversidades presentes na tutoria, compreendendo que estas enriquecem a equipe como um todo - no que se refere à concretização da proposta pedagógica do Curso. Sendo assim, embora haja uma circulação mais constante da equipe docente do Curso diante da abertura de diferentes interdisciplinas a cada eixo articulador, tendo em vista o objeto de estudo específico de cada uma, pode-se dizer que há uma diretriz de preferencialidade pela permanência da tutoria, a qual auxilia os docentes recém ingressos no Curso na apropriação tecnológica e da proposta pedagógica deste, bem como, entre outras contribuições, fortifica e propaga os vínculos de reciprocidade cognitivos/ sociais/ afetivos entre os discentes e destes com os docentes, vínculos estes imprescindíveis quando se objetiva acréscimos qualitativos nos processos de ensino e de aprendizagem (GELATTI, 2005).

\section{Recursos informatizados utilizados pela tutoria e demais partícipes}

A apropriação dos recursos tecnológicos informatizados propostos no Curso é tanto um desafio para os alunos e docentes quanto para os tutores. Tendo em 
vista as correntes e aceleradas inovações técnico-científicas presentes em nossos contextos sociais, que impulsionam a emergência e a aplicabilidade de uma significativa diversidade de recursos no cenário educacional, há necessidade de os sujeitos da educação - e o tutor o é - apropriarem-se desses recursos informatizados do ponto de vista pedagógico, em patamares cada vez mais amplos, pela natureza das funções tutoriais. Esse tópico trata, pois, da apresentação de alguns desses recursos que compõem o universo de trabalho do tutor do PEAD.

O ROODA $A^{5}$ (Rede c $O O$ perativa $D$ e $A$ prendizagem) é uma das plataformas - ou ainda, ambientes virtuais - utilizada pela UFRGS em cursos presenciais e a distância, sendo essa a principal plataforma utilizada no Curso PEAD. Ela começou a ser desenvolvida no ano de 2000 pelo Núcleo de Tecnologia Digital aplicada à Educação (NUTED), estando este vinculado à Faculdade de Educação e ao Centro Interdisciplinar de Novas Tecnologias na Educação (CINTED) da UFRGS. Em 2003, o ROODA, ambiente baseado na ideia de software livre, é reconhecido institucionalmente, passando a fazer parte do projeto de Educação a Distância da UFRGS. Em 2005, foi lançada uma nova versão do ROODA, sendo difundida na Universidade em diferentes disciplinas de Graduação, Pós-graduação e Extensão. Em 2006, essa plataforma passou a ser localizada no servidor da UFRGS. Desde então, até o presente momento, o ROODA vem sendo continuamente aperfeiçoado "[...] a partir das necessidades educativas que vão surgindo ao longo de sua aplicação na comunidade acadêmica", com a finalidade de "que se possa adaptá-lo às realidades educacionais da universidade", muito embora, para isso, ainda se tenha um grande caminho a percorrer (UFRGS, 2009).

Segundo Behar (2001), o desenvolvimento do ROODA surgiu da necessidade de um ambiente que não apresentasse uma reprodução do ensino linear e fechado, a exemplo das salas de aula em moldes "tradicionais". Conforme a autora:

A concepção epistemológica deste ambiente embasa-se na teoria piagetiana, segundo a qual, a construção do conhecimento se dá através da interação do sujeito com o objeto. É através deste processo que o sujeito se coloca no mundo e, com ele, estabelece uma ligação. (BEHAR, 2006, p. 6)

5 Ambiente virtual disponível no site institucional $<$ http://www.ead.ufrgs.br/rooda $>$ (somente para usuários cadastrados) e no site do ROODA, <http://rooda.edu.ufrgs.br>. 
Nesta perspectiva teórica, o ROODA caracteriza-se como um ambiente virtual de aprendizagem interativo, o qual disponibiliza funcionalidades síncronas e assíncronas via Web que permitem a interação/comunicação entre alunos, tutores e docentes. Ele consiste num "[...] lugar onde possam ser realizadas contínuas interações, trocas de idéias e reflexões através do ambiente e, conseqüentemente, promover o aprender a aprender dos sujeitos envolvidos neste novo modelo educacional" (BEHAR, 2001, p. 90).

Entretanto, a prática docente e a tutorial no que se refere ao uso de um determinado ambiente virtual pode ou não apresentar coerência com a abordagem epistemológica que norteia a construção deste ambiente, seja a última qual for. Nesse sentido, este mesmo ambiente pode suportar uma atividade centrada na ação vertical do professor sobre o aluno, independentemente da existência de ferramentas voltadas a propostas pedagógicas que possam proporcionar interação, reflexão e construção de conhecimento em uma perspectiva interacionista. Sendo assim, algumas ferramentas podem perder seu sentido ou serem re-significadas pelos sujeitos que as utilizam.

No ambiente ROODA (BEHAR, 2001, 2005, 2006), várias ferramentas que são utilizadas na educação a distância encontram-se dentro de um mesmo sistema. Neste artigo, destacamos as ferramentas: A2, Fórum, Bate-papo, Diário de Bordo, Webfólio, Lista de Discussão, Aulas e Biblioteca, todas utilizadas pelos tutores do Curso:

a) A2: Ferramenta que possibilita a comunicação síncrona on-line entre dois usuários conectados no ROODA. O A2 apresenta uma lista com o nome de todos os usuários que estão on-line. Essa ferramenta foi criada para permitir que o aluno visualize os outros alunos conectados, compartilhando o mesmo espaço virtual com eles (BEHAR, 2001), sendo também utilizada pelos tutores e pelos docentes como uma alternativa de comunicação entre pares e demais partícipes do Curso.

b) Fórum: Ferramenta destinada à comunicação assíncrona on-line e ao registro e acesso a este, geralmente utilizada para debate e reflexão entre alunos, tutores e/ou docentes sobre temáticas relacionadas às interdisciplinas.

c) Bate-papo: Ferramenta destinada à comunicação síncrona on-line entre os usuários, embora, no ROODA, ela permita também salvar as mensagens digitadas e, desta forma, possa servir de referência aos usuários que participaram ou não do momento síncrono. Essa ferramenta é geralmente empregada para a troca de informações, discussão e reflexão entre alunos, tutores e/ou docentes sobre questões referentes às interdisciplinas. 
d) Diário de Bordo: Ferramenta que possibilita ao usuário o registro pessoal de construções, aprendizagens, reflexões, inquietudes etc., permitindo, no âmbito educacional, o acompanhamento avaliativo processual e a intervenção pedagógica do docente e do tutor em relação aos registros efetuados pelos alunos.

e) Webfólio: Ferramenta que consiste em um portfólio on-line de um usuário ou de um grupo de usuários na $\mathrm{Web}$ (geralmente localizado em um ambiente virtual, tal como o ROODA), o qual pode ser entendido como um repositório de processos e produtos referentes a registros e produções do usuário (aluno), que permite organização, publicação de arquivos e consulta por parte de usuários. No Curso PEAD, essa é uma das ferramentas mais utilizadas pelo docente e tutor para o acompanhamento avaliativo das produções do aluno e para a intervenção pedagógica.

f) Lista de Discussão: Ferramenta de comunicação assíncrona, gerenciável pela Internet, que permite a um grupo de usuários (alunos, tutores, docentes etc.) o cadastro de uma lista de endereços eletrônicos no ROODA para a troca de mensagens eletrônicas entre todos os membros do grupo.

g) Aulas: Ferramenta que apresenta recursos e espaço on-line para a publicação, via editor $W e b$, das atividades (aulas) dentro do ambiente, podendo a publicação destas ser efetuada por docentes e/ou tutores.

h) Biblioteca: Ferramenta que disponibiliza recursos e espaço on-line para a publicação de materiais de apoio (artigos, trabalhos, apresentações etc.) dentro do ambiente, a serem compartilhados com todos os usuários, podendo ser postados por alunos, tutores, docentes.

Além do ambiente ROODA, outros recursos e ambientes informatizados são utilizados pelos tutores, pelos alunos e demais integrantes do Curso, tais como:

a) Blogs: é um site que permite ao usuário a publicação de textos e arquivos, sendo geralmente utilizado para a criação de diários virtuais e a criação de páginas pessoais na Web (World Wide Web), permitindo uma ação coletiva entre autores e leitores dos blogs e a formação de redes de hipertextos. No PEAD, os weblogs ou blogs são utilizados como diários on-line construídos pelos alunos, relativos a sua trajetória pessoal-profissional e a de como alunos do Curso; como alternativa (geralmente secundária) para a publicação de atividades/ aulas (pois o ROODA, por ser o site oficial do Curso, compreende prioritariamente essa finalidade); como espaço on-line para trocas 
entre partícipes (alunos, tutores, docentes, coordenadores etc.) do mesmo polo e/ou entre polos, entre outras funções que vão sendo ampliadas ao longo do Curso. Consiste, assim, em mais um instrumento para o acompanhamento avaliativo dos alunos e do Curso como um todo.

b) WIKI: é uma ferramenta que proporciona espaços e recursos para a escrita e autoria coletiva, permitindo a construção de hipertextos a partir do próprio navegador. Essa ferramenta possibilita a escrita cooperativa, sendo que a correção, o acréscimo de informações e a alteração do conteúdo de toda a página $w e b$ pode ser realizada por usuários autorizados (alunos, tutores, docentes, coordenadores etc.). O WIKI utilizado no PEAD é o PBWIKI.

Além de possuir domínio tecnológico suficiente para atuar com familiaridade, agilidade e aptidão nos ambientes virtuais e com os recursos/ ferramentas informatizadas em questão, o tutor precisará refletir sobre a proposta pedagógica e sobre suas próprias concepções e práticas educacionais, intencionando que esta proposta se concretize em caráter participativo, interativo e contextualizado. Dessa forma, Gelatti considera que é essencial para o tutor o investimento na "[...] reflexão sobre os fundamentos epistemológicos e educacionais e, mais do que isso, numa nova concepção paradigmática de ser humano-sociedade-mundo" (2007, p. 6-7). Nesse panorama:

As tecnologias de informação e comunicação utilizadas na educação a distância trazem novas possibilidades de utilização e novos espaços/desejos na formação. Essa formação consiste em um processo de educação profissional que entende o trabalho da [...] tutoria como apoio importantíssimo na ação pedagógica. Traduz-se numa forma de atender às necessidades de contínua formação dos [...] tutores frente às profundas transformações econômicas, sociais e tecnológicas vigentes. (ERDMANN, GELATTI, 2003, p. 305)

Portanto, para que os objetivos do Curso sejam atingidos, o tutor precisa apropriar-se das tecnologias informatizadas - as quais são mais enfaticamente utilizadas no Curso - saber empregá-las criticamente de maneira adequada às características e necessidades dos alunos, tendo como referência a proposta pedagógica que embasa a ação formativa do Curso. 


\section{Concretização da Proposta Pedagógica de Atuação da Tutoria}

As funções pedagógica, social e organizativa dos tutores, apresentadas conforme as diretrizes teórico-práticas do Curso, configuram um tutor ativo e participante nos processos de ensino e de aprendizagem. O objeto de trabalho do tutor e o do docente se encontram constantemente, até porque ambos trabalham por um significativo objetivo em comum: a formação dos alunos no que compete à proposta do Curso. No entanto, cada um destes profissionais apresenta atribuições específicas. As atribuições do docente estão expressas no Guia do Professor (CARVALHO; NEVADO; BORDAS, 2006b).

Considerando os espaços/tempos formativos já oportunizados aos tutores, alunos e docentes ao longo do desenvolvimento do Curso, pode-se dizer que foi possibilitada clareza teórica das atribuições do tutor e do docente a esses profissionais, tendo cada um destes responsabilidades específicas. Além disso, tanto o Guia do Tutor (2006c) como o Guia do Aluno (2006a) apresentam as atribuições/ funções da tutoria do Curso.

Além da formação inicial da tutoria realizada a cada eixo articulador pois novas demandas, interdisciplinas e tutores passam a fazer parte da rotina de trabalho desta - a realização de encontros sistemáticos presenciais e virtuais (ocorridos em média uma vez por semana) de formação continuada da tutoria do Curso - ministrados pelas coordenações geral e pedagógica, como também pela coordenação da tutoria do Curso - propiciam espaços/ tempos para o compartilhamento, avaliação e re-direcionamento de concepções e práticas. Propostas de avaliação da atuação da tutoria são debatidas e efetivadas, buscando-se envolver todos os partícipes do Curso.

Para garantir esse espaço semanal de formação continuada dos tutores tanto do polo como dos da sede do Curso - em grande parte, realizados na FACED/ UFRGS - foi oferecida até o ano de 2007, como uma das alternativas, uma disciplina curricular semestral nos Programas de Pós-Graduação em Educação e em Informática na Educação da UFRGS, ministrada pela coordenação geral e/ou vice-coordenadora do Curso PEAD - como foi o caso da disciplina Tutoria em Educação a Distância I. No segundo semestre de 2007, iniciou-se o curso de pós-graduação lato sensu (especialização) Tutoria em Educação a Distância, oferecido aos tutores do PEAD com o propósito de formação inicial e continuada.

Nós, autores desse artigo, tivemos como colegas de disciplina tutores e docentes do Curso PEAD. Nesse sentido, cabe frisar que todos os tutores apresentam como formação acadêmica, pelo menos, um curso de graduação concluído (podendo este ser nas áreas de conhecimento Humanas, Exatas, Saúde, entre 
outras); a maioria destes já realizaram ou estão realizando cursos de especialização, mestrado e, até mesmo, doutorado. Conforme o que foi exposto anteriormente, pela natureza de suas funções, os tutores do polo não precisam ter, necessariamente, formação específica em qualquer área das interdisciplinas; já os tutores da sede têm formação geral ou específica nas interdisciplinas (2006c, p. 25-27).

O oferecimento dessa disciplina pela UFRGS, entre outras alternativas, permite que seja viabilizado administrativamente o vínculo do tutor do PEAD à universidade, sendo assim identificado como estagiário ou bolsista de pósgraduação para a atuação nas "[...] Unidades Operacionais e na Sede, apoiando o trabalho dos professores e dos alunos do Curso" (BORDAS; CARVALHO; NEVADO, 2005, p.159).

Na medida em que os alunos do PEAD apresentam mais familiaridade com as tecnologias informatizadas, por um lado deixam de necessitar e/ou solicitar dos tutores determinados saberes e auxílios práticos devido ao fato de os primeiros, na maioria, já se autogerirem diante de muitos dos desafios tecnológico-educacionais propostos pelas interdisciplinas; por outro lado, os alunos passam a exigir dos tutores saberes mais complexos, atuações que implicam contribuições gradualmente mais qualitativas, comportando contínuos aperfeiçoamentos teóricopráticos por parte de todos os tutores. Acrescido a isso, há velozes transformações no universo das tecnologias informatizadas aplicadas ao campo educacional e, por outro lado ainda, há necessidade de readequações da proposta pedagógica tanto quanto à atuação tutorial do Curso quanto a outros de seus aspectos, frente às singularidades presentes nos alunos de cada polo e, propriamente, às particularidades de cada contexto que compõem determinado polo.

A partir disso, Gelatti aponta que "o Sistema de Tutoria, quando bem estruturado e atuante, de acordo com a proposta do Programa, é um dos principais responsáveis pelo sucesso da experiência da educação a distância", podendo afirmar-se que "[...] o tutor é a 'presencialidade necessária' na educação a distância [...]” (2005, p. 66). Isto não exime, de maneira alguma, o imprescindível papel do docente como principal responsável pelo planejamento, avaliação, intervenção e mediação do processo educativo.

Sucessos e dificuldades estão presentes na atuação dos tutores. Nem todos estes compreendem e se inserem em sua completude na proposta pedagógica do Curso PEAD e nas ações que advém dela. Há específicas exigências teórico-práticas que caracterizam o "ser tutor". Desde a primeira iniciativa de formação inicial proposta aos candidatos que desejavam ser tutores do Curso, concretizada no ano de 2006, a coordenação geral do Curso frisou que o fato de algum candidato não ser selecionado para esse trabalho não implica, de forma alguma, em ser "melhor" ou "pior" tutor, mas que, para essa proposta de tutoria que se deseja nesse Curso, partindo da escolha de uma concepção tecnológico- 
educacional específica, o perfil profissional apresentado pode não comportar as exigências básicas propostas pelo Curso. Nessa perspectiva, também tutores já atuantes no Curso podem não corresponder mais às expectativas de trabalho da tutoria, tendo em vista, entre outros aspectos, o movimento de rupturas de concepções e práticas que o Curso vai tomando em sua constituição. Cabe salientar, nesse contexto, que o Curso PEAD iniciou-se no $2^{\circ}$ semestre do ano de 2006; atualmente, ou seja, no $1^{\circ}$ semestre de 2009, o Curso se encontra no desenvolvimento do sexto eixo articulador - de um total de 9 eixos propostos, que resultam em quatro anos e meio de Curso.

Sendo assim, a prática pedagógica do Curso e, mais especificamente, a da tutoria têm tomado rumos diferentes do que foi inicialmente proposto. Algumas das funções tutoriais (pedagógica, social e organizativa), por sua vez, também sofreram transformações durante o processo de implementação - e, de certa forma, espera-se que isso ocorra. Há uma distância relativa do que já foi e do que é proposto em relação ao que até o momento foi alcançado no que diz respeito à atuação da tutoria, bem como à da equipe do Curso em geral. Por um lado, ocorrem alterações do que é proposto quando aplicado na prática devido a atravessamentos antes não previstos os quais surgem com a implementação da proposta. Por outro lado, há entraves pedagógicos que ainda precisam ser superados. Enquanto que, inicialmente, enfrentou-se com mais ênfase dificuldades referentes à implementação da proposta tutorial devido à compreensão parcial de alguns tutores e docentes quanto ao caráter da proposta de EAD do Curso, permanece, atualmente, o desafio de estabelecer limites funcionais entre o trabalho docente e o do tutor (ainda que ambos trabalhem colaborativamente com o mesmo objeto de trabalho), pois, por vezes, este último assume mais atribuições docentes do que o proposto, além das gerais designadas pelo Curso, e/ ou o docente fica sobrecarregado de atividades da interdisciplina, sem poder dar o devido atendimento qualitativo a cada aluno.

Além disso, há também problemáticas de ordem geral do Curso as quais interferem direta ou indiretamente no trabalho do tutor, tais como empecilhos quanto a aprendizagens de cunho tecnológico por parte dos alunos que, muitas vezes, dificultam, ou até mesmo, os impedem de avançar em um campo mais pedagógico. Embora se tenha presente que novos e mais complexos serão os saberes tecnológicos exigidos dos alunos no decorrer do Curso, esses saberes não devem ser tão numerosos e complexos a ponto de não serem aprendidos por eles - principalmente, pela limitação de tempo disponível para isso e pela gama de atividades simultâneas propostas pelo próprio Curso, resultante da soma das proposições de todas as interdisciplinas semestrais, as quais, preferencialmente, requerem mais atenção dos mesmos (além das atividades decorrentes do exercício profissional, pois há uma parcela de alunos, embora não quantitativamente significativa, que 
trabalha 60 horas semanais; uma parcela majoritária dos alunos trabalha, em média, 35 horas semanais) - e, em decorrência disto, resultarem em obstáculos para o estudo dos objetos específicos das interdisciplinas, mesmo que a apropriação tecnológica informatizada também seja um dos objetivos em questão.

A redução da quantidade de atividades propostas por cada interdisciplina do Curso para centrar-se nas atividades mais relevantes e qualitativas tem sido um dos desafios presentes a cada eixo articulador. Em função da problemática exemplificada, quanto mais atividades forem propostas aos alunos, maior será o tempo e trabalho necessários para a avaliação das mesmas (incluindo a intervenção pedagógica) por parte dos tutores e docentes, dificultando assim que ambos possam focar o seu fazer em ações que qualifiquem mais o processo educativo, como, por exemplo, a articulação de debates e o levantamento de problematizações sobre as temáticas trabalhadas em fóruns das interdisciplinas. Nesse sentido, evidencia-se a importância de se repensar o fazer educativo e suas implicações frente ao que se deseja como proposta de formação de professores a distância na educação superior.

A partir disso, trabalha-se para que se compreenda o que levou ao surgimento do que é considerado como dificuldade na atuação tutorial e na dos partícipes do Curso como um todo, intencionando compreender e analisar esse processo (auto)avaliativo como elemento possibilitador de construções de proposições e ações fundamentadas na realidade em questão, objetivando superar dificuldades e qualificar a atuação da tutoria como "significativa" no apoio docente, sendo assim imprescindível o investimento permanente em formação continuada específica da tutoria (GELATTI, 2005, p. 71). Criar significado implica ter um entendimento de ser humano como essencialmente "projeto" e, conforme Ben e Schuelter (2004), é ser ação em que o seu agir lança-se sobre os fatos da sua existência e da qual faz parte todo e qualquer novo significado que, por vezes, abre ao sujeito novas funcionalidades e possibilidades. Compreender o tutor como um "projeto", de acordo com Gelatti $(2007,2005)$, supõe ainda "vir-aser" educando e educador como polos de uma mesma totalidade, de um mesmo "ser" que se desafia a estar continuamente em processo de qualificação de sua própria atuação e do contexto no qual se insere.

\section{Considerações finais}

No presente artigo não se teve o objetivo e a pretensão de abarcar todos os aspectos relativos à proposta pedagógica da atuação da tutoria, até porque 
a maioria (e não foram poucas) das orientações teórico-práticas propostas aos tutores ao longo do desenvolvimento do Curso não consta no Guia do Tutor (2006c), pois se efetivaram por meio dos encontros/ reuniões presenciais e virtuais de formação inicial e continuada. Houve, sim, a preocupação dos autores em compilar as diretrizes básicas do objeto de estudo em questão, acrescidas de algumas dessas orientações.

As equipes de trabalho do Curso PEAD/UFRGS, nas quais os tutores estão incluídos, são responsáveis desde o planejamento da proposta pedagógica à concretização, consolidação e, quando necessário, re-direcionamento desta, dinamizando-se e interagindo-se entre si numa criação coletiva, valorizandose a unidade e as possíveis diferenciações, no intuito de incentivar a criação e o fortalecimento de comunidades de aprendizagem.

As funções do Tutor do Polo assim como as do Tutor da Sede do Curso PEAD, apresentadas no Guia do Tutor (2006c), denotam um intenso campo de aprendizagem e de formação humana, desde o domínio de novas alternativas tecnológico-educacionais para a construção de conhecimentos num ambiente colaborativo até a compreensão da proposta pedagógica orientadora da ação tutorial.

Sendo assim, os pressupostos teóricos do PEAD são contrários a propostas formativas a distância que vislumbrem uma divisão funcional de profissionais em um corpo conteudista (que planeja o conteúdo curricular e as propostas de trabalho), em um corpo técnico (que produz os materiais didáticos do ponto de vista das mídias) e em um outro implantador (que concretiza determinada proposta de trabalho planejada por "conteudistas") - sendo este último geralmente composto por tutores que, muitas vezes, não possuem formação apropriada para assumir tal responsabilidade. Essa classificação, analogicamente, remete à concepção fordista, isto é, a um modelo administrativo-industrial, que teve o seu auge na sociedade na primeira metade do século XX, caracterizado pela produção vertical em massa e em série, utilizando-se de princípios de padronização e simplificação tayloristas.

Já o Curso PEAD requer profissionais (tutores e docentes) que tenham conhecimento da atuação na totalidade do processo educativo, que trabalhem conjuntamente diante do desafio de formar alunos (professores em serviço) a partir de seus saberes educacionais e de novos saberes aprendidos para refletir e re-significar a prática escolar, com vistas a uma prática coerente com o discurso pedagógico.

Nesse sentido, de acordo com o documento Referenciais de Qualidade para a Educação Superior a Distância - 2007 (BRASIL, 2009, p. 7), desenvolver um projeto na modalidade EAD implica na necessidade de compreender a educação como fundamento elementar, antes de se pensar no modo de organização a distância. A EAD precisa, em primeira instância, "ser entendida no 
contexto da Educação Geral, ou seja, não se trata de uma educação diferente, mas um modo diferenciado de se fazer Educação" (FRANCO, 2004, p. 9).

Coerentemente com a proposta pedagógica do Curso, vivenciar a tutoria significa colaborar ativamente na construção dos processos de ensino e de aprendizagem, propiciando interações contínuas e qualitativas entre todos os envolvidos, tendo presente suas funções pedagógica, social e organizativa. É o que se deseja como atuação tutorial.

\section{REFERÊNCIAS}

BEHAR, P.A. et al. O Processo Avaliativo do ROODA: uma proposta interdisciplinar. Renote Revista Novas Tecnologias da Educação, Porto Alegre, v. 4, n. 1, 2006. ; COLOMBO, M.C.; AMARAL, C.B. A categorização das funcionalidades do ambiente virtual ROODA. Renote Revista Novas Tecnologias na Educação, Porto Alegre, v. 3, n. 1, 2005.

; KIST, S.; BITTENCOURT, J. A caminho de um ambiente de aprendizagem à distância - ROODA - Rede cOOperativa De Aprendizagem. In: SIMPÓSIO BRASILEIRO DE INFORMÁTICA NA EDUCAÇÃO, 12., 2001, Vitória - Espírito Santo. Anais... Vitória, 2001. v. 1. p. 89-95.

BEN, P.V.; SCHUELTER, W. Interação usuário-hipertexto em curso on-line. Trabalho apresentado no IV Congresso de Língua e Literatura, Unoes. Joaçaba, 2004.

BORDAS, M.; CARVALHO, M.J.C.; NEVADO, R.A. Formação de Professores: pressupostos pedagógicos do curso de Licenciatura em Pedagogia/EAD. Informática na Educação: teoria \& prática, Porto Alegre, v.8, n.1, p. 143-167, jan./jun. 2005.

BRASIL. MEC. SEED. Referenciais de Qualidade para a Educação Superior a Distância. Disponível em: <http://portal.mec.gov.br/seed/arquivos/pdf/legislacao/ refead1.pdf $>$. Acesso em: 19/01/2009.

CARVALHO, M.J.; NEVADO, R.A.; BORDAS, M.C. Guia do Aluno. Curso de Licenciatura em Pedagogia a Distância: Anos Iniciais do Ensino Fundamental. Faculdade de Educação (FACED). Porto Alegre, 2006a. 
. Guia do Professor. Curso de Licenciatura em Pedagogia a Distância: Anos Iniciais do Ensino Fundamental. Faculdade de Educação (FACED). Porto Alegre, 2006b.

. Guia do Tutor. Curso de Licenciatura em Pedagogia a Distância: Anos Iniciais do Ensino Fundamental. Faculdade de Educação (FACED). Porto Alegre, 2006c.

ERDMANN, B.M.; GELATTI, L.S. et al. Monitoria e tutoria: linhas de força, intensidades e experiências no contexto da PUCRS Virtual. In: MEDEIROS, M.F. de; FARIA, E.T. (Orgs.). Educação a distância: cartografias pulsantes em movimento. Porto Alegre: EDIPUCRS, 2003.

FRANCO, S.R.K. (Org.). Educação a Distância na Universidade Federal do Rio Grande do Sul. Porto Alegre: UFRGS, 2004.

GELATTI, L.S. A formação de professores para a apropriação da educação a distância: caminhos, rupturas e desafios. Anteprojeto de tese (Doutorado em Educação) - Programa de Pós-Graduação em Educação da Universidade Federal do Rio Grande do Sul, Porto Alegre, 2007.

. A formação de educadores de jovens e adultos: potencializadora e potencializada pela educação a distância? Dissertação (Mestrado em Educação) - Faculdade de Educação, Pontifícia Universidade Católica do Rio Grande do Sul, Porto Alegre, 2005.

SANTOS, B.S. A universidade no século XXI: para uma reforma democrática e emancipatória da universidade. 2. ed. São Paulo: Cortez, 2005.

UFRGS. NUTED. Núcleo de Tecnologia Digital aplicada à Educação. ROODA. Rede Cooperativa de Aprendizagem. Disponível em: $<$ http://www.nuted.edu. ufrgs.br/nuted/projeto_rooda.html>. Acesso em: 28/01/2009.

Texto recebido em 18 de março de 2009.

Texto aprovado em 11 de abril de 2009. 